\title{
The First Total Synthesis of 2,3,6-Tribromo-4,5-dihydroxybenzyl Methyl Ether (TDB) and Its Antioxidant Activity
}

\author{
Jae-Kon Kim, Jung Hyun Noh, Sungeun Lee, Jae Sue Choi, Hongsuk Suh," \\ Hae Young Chung, ${ }^{\ddagger}$ Yeong-Ok Song, and Won Chul Choi ${ }^{\#}$ \\ Deparment of Chemisty and Chemistry Institute for Functional Materials, Pusan National University, Pusan 609-735, Korea \\ ${ }^{\circ}$ Department of Food and Life Science. Pukyong National University, Pusan 608-737, Korea \\ "College of Pharmacy, Pusan National Unwersity, Pasan 609-735, Korea \\ SDeparment of Food Science \& Nutrition, Pusan National University; Pusan 609-735, Korea \\ Deparment of Biology, Pasam National Linversity, Pasan 609-735, Korea
}

Recened January 30, 2002

Keywords : 2,3,6-Tribromo-4,5-dihydroxybenzyl methyl ether, TDB. DPPH, Peroxynitrite.

Several bromophenols were isolated from Symphyocladia latiuscula (I larvey) Yamada, which is a member of the family Rhodomelaccac. ${ }^{1-4}$ The antioxidant activity, of the methanolic extract of the $S$. latiuscula on peroxynitrite (ONOO ) and 1.1-diphenyl-2-picryllydrazyl (DPPI I) radicals was reported by us. ${ }^{5.6}$ We also isolated 2,3,6-1ribromo-4,5dihydroxybenzyl methyl ether (TDB) from this methanolic extract and identified the structure depending on spectroscopic evidence. The reaction of nitric oxide and supcroxide generates peroxynitrite, which is a cylotoxicant. Peroxynitrite can oxidize sullhyryls, lipids, amino acids, and nucleotides. ${ }^{8}$ It was demonstrated that excessive formation of peroxynitrite may cause $\Lambda$ lzheimers disease, rheumatoid arthritis, cancer, and atherosclerosis."<smiles>COCc1c(Br)c(O)c(O)c(Br)c1Br</smiles>

\section{2,3,6-tribromo-4,5-dihydroxybenzyl methy ether}

In this report, we reveal the first total syntheses of 2,3,6tribromo-4,5-dihydroxybenzyl methyl ether and its scavenging activity of peroxynitrite and DPPH radicals.

The synthetic route of the 2,3,6-tribromo-4,5-dihydroxybenzyl methyl ether (6) began with the protection of 3.4dihydroxybenzaldehyde (1) with acetone and phosphorus pentoxide in toluene to generate 2,2-dimethyl-1,3-benzodioxole-5-carbaldehyde (2) in $85 \%$ yield. Aldehyde 2 was reduced with disobutylaluminum hydride in $\mathrm{CH}_{2} \mathrm{Cl}_{2}$ at -78 " $\mathrm{C}$ to provide alcohol 3 in $85 \%$ yield. (2,2-Dimethyl-1.3benzodioxol-5-yl)methanol (3) was brominated using bromine in concentrated $\mathrm{HCl}$ to afford tetrabromo compound 4 in $7 \%$ yield. In this reaction, the unwanted compound dibrominated on the benzene ring was isolated as the major product with $40-50 \%$ yield. The resulting 4,5,7-tribromo6-(bromomethyl)-2,2-dimethyl-1,3-benzodioxole (4) was treated with calcium carbonate in acpueous dioxame to provide alcohol 5 in $84 \%$ yield. Finally, (4,6,7-tribromo-2,2dimethyl-1.3-benzodioxol-5-yl) methanol (5) was treated
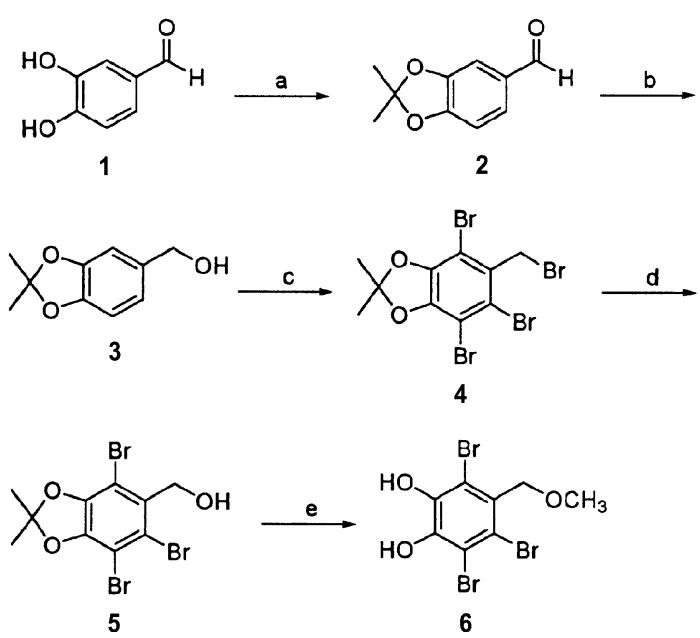

Scheme 1. Rection conditions; a) Acctons. $\mathrm{P}_{7} \mathrm{O}_{5}$. toluene; b) DIBAl,-hexane. $\mathrm{CH}_{2} \mathrm{Cl}_{2},-78{ }^{\circ} \mathrm{C} ; \mathrm{c}$ ) $\mathrm{Br}_{2}$, conc. $\mathrm{HCl} \cdot \mathrm{H}_{2} \mathrm{O}: \mathrm{dj}$ $\mathrm{CaCO}_{3} \mathrm{II}_{2} \mathrm{O}$. dioxane; e) conc HCl, MeOII.

with concentrated $\mathrm{HCl}$ and $\mathrm{MeOH}$ for $8 \mathrm{~h}$ at reflux to generate the desired final natural product 2,3,6-tribromo4,5-dihydroxybenzyl methyl ether (TDB) (6) in $22 \%$ yield. In the last step, we tried to improve the yield by using numerous conditions, which led to the debromination of the aromatic bromo groups. The spectroscopic data ${ }^{10}$ of the synthesized natural product 6 was identical with that of the naturally occurring 2,3,6-tribromo-4,5-dilyddroxybenzyl methyl ether. ${ }^{\text {? }}$

The synthesized natural product TDB (6) was assayed for its ability to scavenge peroxynitrite $\left(\mathrm{ONOO}^{-}\right)$and $1,1-$ diphenyl-2-picrylhydrazyl (DPPH) radicals (Table 1). ${ }^{1.12}$ As shown in Table 1, the DPPH radical scavenging activity of synthesized natural product TDB (6) ( $\left.\mathrm{CC}_{s 0}=7.8 \mu \mathrm{M}\right)$ appears to be slightly higher than that of the naturally occuming TDB (IC $\mathrm{C}_{50}=10.5 \mu \mathrm{M}$ ). This is possibly caused by the impurity in the sample of the naturally occurring TDB. This result also confirms that TDB has higher antioxidant activity as compared with $\mathrm{L}$-ascorbic acid $\left(\mathrm{IC} \mathrm{C}_{50}=28.44 \mu \mathrm{M}\right)$. Moreover, the synthesized natural product TDB (6) shows strong seaveng- 
Table 1. Perosynitrite and DPPH Radical Scavenging Effect of Synthetic TDB $6^{\circ}$

\begin{tabular}{lcc}
\hline & $\mathrm{DPPH}$ & $\mathrm{ONOO}^{-}$ \\
\cline { 2 - 3 } & $\mathrm{IC}_{51}(\mu \mathrm{M})$ & $\mathrm{IC}_{51}(\mu \mathrm{M})$ \\
\hline Synthetic TDB 6 & 7.8 & 0.012 \\
Natural TDB & 10.5 & 0.013 \\
L-Ascorbic acid & 28.4 & \\
Penicillamine & & 3.36
\end{tabular}

"All the values are stated as the mean of at least three determinations.

ing activity of perosynitrite $\left(\mathrm{ONOO}^{-}\right)\left(\mathrm{IC}_{5 i j}=0.012 \mu \mathrm{M}\right)$ as shown in Table 1 .

In conclusion, we firstly synthesized 2.3,6-tribromo-4.5dihydroxybenzyl methyl ether (TDB) and confirmed that TDB has strong peroxynitrite and DPPH radical scavenging activity.

Acknowledgment. This work was supported by a grant (2002 of Marine Developnent Division) of the Ministry of Maritime Affairs \& Fisheries.

\section{References and Notes}

1. Yamada. Y. Sci. Pap. List. Algolo. Res. Fac. Sci. Hohkaido Imp. Lin: 19+1. 2. 195.

2. Kurata. K.: Amiya. T. Phyochentistry 1980. 19.141.

3. Kurihara. H.: Mitani. T.: Kawabata. J.: Takahashi. K. Fish. Sci. $1999,65,300$.

4. Kurata, K: Amiya, T. Chem. Lett. $1980,279$.

5. Park: H. I.: Choi J. S.: Chung. H. Y. J. Konem Fisheries Soc. 1998. 31.927

6. Jung. H. A.: Choi. H. R.: Park. H. J.: Choi. J. S.: Choi. W. C. J. Agric. Food Chem. 2001. 19.3614.

7. Park H. J. Chung. H. Y.: Kim. J.: Choi. J. S. J. Fish Sci. Tech. 1999, 2.1.

8. Balavoine G. G. Geletii, Y. V. Kintic Oxide 1999. 3.40.
9. Squadrito. G. L.: Pryor. W. A. Free Radical Biol Med. 1998, 25. 392.

10. Selected data for synthetic IDB: white powder. mp 124-125 ${ }^{\circ} \mathrm{C}$. Rfo. $38\left(\mathrm{SiO}_{2},{ }^{2} \cdot 6 \mathrm{MeOH}-\mathrm{CH}_{2} \mathrm{Cl}_{2}\right):{ }^{\mathrm{H}} \mathrm{H}-\mathrm{NMR}\left(500 \mathrm{MHz}, \mathrm{CD}_{3} \mathrm{OD}\right)$ $\delta 3.40(\mathrm{~s}, 3 \mathrm{H}), 4.81(\mathrm{~s}, 2 \mathrm{H}),{ }^{13} \mathrm{C}-\mathrm{NMR}\left(125 \mathrm{MHz}, \mathrm{CD}_{3} \mathrm{OD}\right) . \delta$ $58.9,76.9,114.7,115.2,119.7 .130 .1,145.1,146.9$, HRFAB MS $m / z 387.7904$ (calculated for $\mathrm{C}_{8} \mathrm{H}-\mathrm{Br} 3 \mathrm{O}_{3} 387.7945$ )

11. DPPH Radical Scavenging Effect: The DPPH radical scavenging effect was evaluated according to the method of Blois. ${ }^{13}$ Methanol solution ( $4 \mathrm{~mL}$ ) of various sample concentration $(1.5-45 \mu \mathrm{M})$ was added to $1 \mathrm{~mL}$ DPPH methanol solution $(1.5 \mathrm{M})$. After mixing gently and leaving for $30 \mathrm{~min}$ at room temperature. the optical density was measured at $520 \mathrm{~nm}$ using a spectrophotometer. The antioxidant activity of each sample was expressed in terms of IC 4 $(a \mathrm{M})$ required to inhibit DPPH radical formation by $50^{\circ} \circ$ and calculated from the log-dose inhibition curve.

12. Peroxynitrite Scavenging Effect: Peroxynitrite scavenging effect was measured by monitoring the DHR 123 according to a modification of the method of Kooy at al. ${ }^{14}$ The stock solution of DHR $123(5 \mathrm{mM})$ in dimethylformamide was purged with nitrogen and stored at $-80^{\circ} \mathrm{C}$. The working solution with DHR 123 (f.c. (final concentration). $5 \mu \mathrm{M}$ ) diluted from the stock solution was placed on ice in the dark immediately prior to the study. The buffer of $90 \mathrm{mM}$ sodium chloride, $50 \mathrm{mM}$ sodium phosphate $(\mathrm{pH} \mathrm{7.4)}$ ), and $5 \mathrm{mM}$ potassium chloride with $100 \mu \mathrm{M}$ (f.c.) diethylenetriamine pentaacetic acid (DTPA) was purged with nitrogen and placed on ice before use Peroxynitrite scavenging by the oxidation of DHR 123 was measured with a microplate fluorescence spectrophotometer FL 500 (Bio-Tek Instruments) with excitation and emission wavelengths of 485 and $530 \mathrm{~nm}$. respectively. at room temperature. The background and final fluorescent intensities were measured 5 mitn after treatment with or without SIN-I (f.c. $10 \mu \mathrm{M}$ ) or authentic perosynitrite (f.c. $10 \mu \mathrm{M}$ ) in $0.3 \mathrm{~N}$ sodium hydroxide. Oxidation of DHR 123 by decomposition of SIN-I gradually increased, whereas authentic peroxynitrite rapidly oxidized DHR 123 with its final fluorescent intensity being stable over time.

13. Blois. M. S. Nature 1958. 26. 1199.

14. Kooy. N. W.: Royall. J. A.: Ischiropoulos. H.: Bechman. I. S. Free Radical Biol Med 1994. 16. 149. 